\title{
Differential Effects of Ethephon and Seniphos on Color Development of 'Starking Delicious' Apple
}

\author{
C. Larrigaudiere and E. Pinto \\ UdL-IRTA, Alcalde Rovira Roure, 177, 25006 Lleida, Spain \\ M. Vendrell ${ }^{1}$ \\ CSIC-CID, Jordi Girona, 18-26, 08034 Barcelona, Spain
}

Additional index words. color, quality, ethylene, ACC metabolism, PAL activity

\begin{abstract}
The differential effects of two color improving products, ethephon an ethylene-releasing compound, and seniphos, a nonethylene-releasing product, were studied on 'Starking Delicious' apples (Malus domestica Borkh L.). Ethephon and seniphos were applied 2 or 3 weeks before commercial harvest. Ethephon- and seniphos-treated fruit showed a significant improvement of peel color associated with a sharp increase in anthocyanin content and chromaticity values. Color improvement in ethephon-treated apples occurred during the preharvest period and cold storage. The seniphos-treated fruit stopped color development in cold conditions. In comparison to the ethephon-treated fruit, the seniphos-treated apples showed lower internal ethylene concentrations and a ripening delay. Both treatments sharply increased the activity of phenylalanine-ammonia-lyase enzyme, which seemed to be the determining factor of color enhancement. The seniphos-treated apples compared to ethephon had higher fruit firmness and lower soluble solids concentrations. Anthocyanin biosynthesis may be enhanced by seniphos treatment without inducing ethylene production or other ripening associated changes. As a consequence, fruit treated with seniphos can be held longer in storage.
\end{abstract}

Fruit peel color is an important quality parameter and marketing attribute that influences consumer acceptance. Color depends on red anthocyanin pigments that are determined mainly by environmental factors such as light and temperature (Tan, 1979). Endogeneous regulators may also be involved in anthocyanin accumulation. The enzyme phenylalanine-ammonia-lyase (PAL: EC 4.3.1.5) is one of these regulators, and it is involved directly as a rate limiting enzyme of the anthocyanin biosynthesis pathway (Faragher and Chalmers, 1977). Another factor is the ripening hormone ethylene, which probably acts more indirectly through some ripening-related changes and particularly through an activation of PAL and anthocyanin synthesis (Faragher and Brohier, 1984; Blankenship and Unrath, 1988).

Since 1963 when Maynard and Swan described the ability of ethephon and its alkene homologs to release ethylene, this compound has been largely used to promote ripening of many fruit (Salunkhe et al., 1991). Ethephon is used commercially to enhance anthocyanin development in 'McIntosh' and other apple cultivars. However, its use has a detrimental effect on storability (Murphey and Dilley, 1988). Seniphos is a phosphorus-calcium mixture that is believed to improve color in various apple cultivars (Phosyn Ltd, personal communication).

The aim of the present study was to compare the effects of two color improving products, ethephon (an ethylene releasing compound) and seniphos (as a nonethylene-releasing compound), on autocatalytic ethylene production, 1-aminocyclopropane-1-carboxylic acid (ACC) metabolism, PAL activity, color improvement and changes in quality attributes before and after harvest.

\footnotetext{
Received for publication 10 July 1995. Accepted for publication 2 Jan. 1996. This work was supported by grants ALI-91-1122-CO3 from Comision Interministerial de Ciencia y Tecnologia and no. 9672 from Instituto Nacional de Investigacion y Tecnologia Agraria y Alimentaria. The product Seniphos was supplied by Phosyn Ltd. The cost of publishing this paper was defrayed in part by the payment of page charges. Under postal regulations, this paper therefore must be hereby marked advertisement solely to indicate this fact.

${ }^{1}$ To whom reprint requests should be addressed.
}

\section{Material and Methods}

Plant material and treatments. 'Starking Delicious' apples were obtained from Lleida (Spain) during summer 1992. A block of trees planted in 1975 was used for these tests. Treatments were assigned to two-tree plots in a completely randomized design. The rootstock was 'Franco'. The same orchard was used for the determinations of quality parameters in years 1993 and 1994.

Ethephon was supplied by Compagnie Française de Produits Industriels (CFPI) in the Union Carbide Formulation $\left(0.48 \mathrm{~kg} \cdot \mathrm{L}^{-1}\right)$ and was applied at a rate of $0.1 \% \mathrm{v} / \mathrm{v}$ in water with a manual sprayer on 9 Sept., 2 weeks before the commercial harvest. Seniphos is a mineral mixture $\left(310 \mathrm{~g} \cdot \mathrm{L}^{-1} \mathrm{P}_{2} \mathrm{O}_{5}, 56 \mathrm{~g} \cdot \mathrm{L}^{-1} \mathrm{CaO}\right.$ and $30 \mathrm{~g} \cdot \mathrm{L}^{-1}$ total $\mathrm{N}: 1 \% \mathrm{NO}_{3}$ and $2 \% \mathrm{NH}_{3}$ ) supplied by the Phosyn Ltd Co. (Phosyn PLC, Pocklington, York NR, U.K.). Seniphos was applied with a manual sprayer on 2 Sept. at a rate of $1 \%$ (company recommendation), 3 weeks before commercial harvest. Controls were sprayed with water.

At harvest, 10 random fruit about $8.5 \mathrm{~cm}$ diameter were taken from the periphery of trees. Color analysis and determination of quality parameters were carried out on seven fruit and ethylene metabolism analysis: ACC, malonyl ACC (MACC) and ACC oxidase on three fruit. In addition a 40-kg sample of fruit was harvested and stored in a chamber at $1{ }^{\circ} \mathrm{C}, 90 \% \mathrm{RH}$ in air for 2 months.

Color analysis. After harvest or removal from cold storage, fruit were gently wiped with a soft cloth and color was measured at four locations, $90^{\circ}$ apart on each fruit. Color measurements were made by placing the head of a portable tristimulus colorimeter (Minolta CR-200) at the midpoint between the stem and the calyx end and recording fruit chromaticity in $\mathrm{L}^{*}, \mathrm{a}^{*}, \mathrm{~b}^{*}$ space coordinates (McGuire, 1992). The meter was calibrated with a white standard before use.

Anthocyanins were extracted from skin by placing four discs, $11 \mathrm{~mm}$ in diameter, in $10 \mathrm{~mL}$ of a solution of 50 methanol : $1 \mathrm{HCl}$ : 49 water. Extraction was carried out overnight at $4{ }^{\circ} \mathrm{C}$ in the dark. Absorbance of extracts was measured with a spectrophotometer at $532 \mathrm{~nm}$ using a molar extinction coefficient of $3.4310^{4}$ (Chalmers et al., 1973). Data were expressed in $\mu \mathrm{mol}$ per $100 \mathrm{~cm}^{2}$. 
Determination of internal ethylene concentration, ACC oxidase activity, and ACC and MACC levels. Internal ethylene concentration was determined by inserting a syringe needle into the central cavity of the fruit and withdrawing 1-mL gas sample. Ethylene was measured using a Hewlett Packard chromatograph equipped with a flame ionization detector.

For the determination of ACC, skin samples were extracted with $80 \%$ ethanol and the ACC content was assayed according to the method of Lizada and Yang (1979). MACC, was measured by analyzing the ACC content of an extract hydrolyzed as described by Hoffman et al. (1982). Yields were routinely about $85 \%$.

ACC oxidase activity was determined in vivo by measuring the conversion of exogenous ACC to ethylene. Thin strips of skin (1 g) were incubated in a $20-\mathrm{mL}$ vial containing $3 \mathrm{~mL}$ of incubation medium (0.4 M mannitol, $10 \mathrm{~mm}$ MES-KOH, pH 6.2) in the presence of $5 \mathrm{~mm}$ ACC and $0.1 \mathrm{~mm}$ cycloheximide (Liu et al., 1985a). Sealed flasks were then incubated for $3 \mathrm{~h}$ and headspace gas samples were taken for $\mathrm{C}_{2} \mathrm{H}_{4}$ analysis.

Extraction and assay of PAL activity. Studies of phenylalanineammonia-lyase (PAL) activity were carried out only during the preharvest period. The activity was determined as previously described (Cheng and Breen, 1991) with slight modifications. Samples (4 $\mathrm{g}$ of apple skin) were grounded in liquid nitrogen until a fine powder was obtained. Polyvinylpyrrolidone (PVP-40, Sigma, 10\% of the fresh weight) was then added and mixed. Ten milliliters of 100 mM sodium borate buffer $\mathrm{pH} 8.8,5 \mathrm{~mm}$ mercaptoethanol and $2 \mathrm{~mm}$ EDTA were added and the mixture gently stirred at $4{ }^{\circ} \mathrm{C}$ until completely thawed. The homogenate was centrifuged at $17000 \times g$ for $10 \mathrm{~min}$. The pellet was then discarded and the supernatant precipi- tated twice with $\left(\mathrm{NH}_{4}\right)_{2} \mathrm{SO}_{4}$ first at $30 \%$ and then at $80 \%$. The protein pellet resulting from the second precipitation $(80 \%)$ was resuspended in $2.5 \mathrm{~mL}$ of borate buffer $50 \mathrm{~mm} \mathrm{pH} 8.8$. The extract was then passed through a G-25 Sephadex column (PD10 Pharmacia Ltd) and eluted with $3.5 \mathrm{~mL}$ of the same buffer. All these operations were carried out at $4{ }^{\circ} \mathrm{C}$ in dim light. The assay mixture contained $33 \mu \mathrm{mol} \cdot \mathrm{L}^{-1}$ phenylalanine, $50 \mathrm{~mm}$ sodium borate buffer $(\mathrm{pH} 8.8)$ and $1 \mathrm{~mL}$ of enzyme extract, in a total volume of $3.0 \mathrm{~mL}$. The substrate was added after $10 \mathrm{~min}$ of preincubation at $30^{\circ} \mathrm{C}$ and the reaction was stopped with $0.1 \mathrm{~mL} 6 \mathrm{~N} \mathrm{HCl}$. PAL activity was determined by the production of cinnamate during $1 \mathrm{~h}$ at $30^{\circ} \mathrm{C}$ and measured by the absorbance change at $290 \mathrm{~nm}$. The enzyme activity was expressed in $\mathrm{nkat} \cdot \mathrm{kg}^{-1}$ fresh weight.

Measurement of firmness. Fruit firmness was measured on two opposite peeled sides of seven fruit using an Effegi portable penetrometer fitted with an 11-mm-diameter probe.

Soluble solids concentration. Soluble solids concentration (SSC) was determined by measuring the refractive index of the juice of the fruit used for firmness determinations. The data represent the means of two opposite pulp sides of seven fruit and are expressed in percent.

\section{Results}

Color improvement. Both treatments, ethephon and seniphos, greatly increased the color of fruit compared to controls. This increase was confirmed by the anthocyanin content analysis (Fig. 1A) and the chromaticity values (Fig. 1B). In the seniphos-treated apples the improvement was noted during the preharvest period
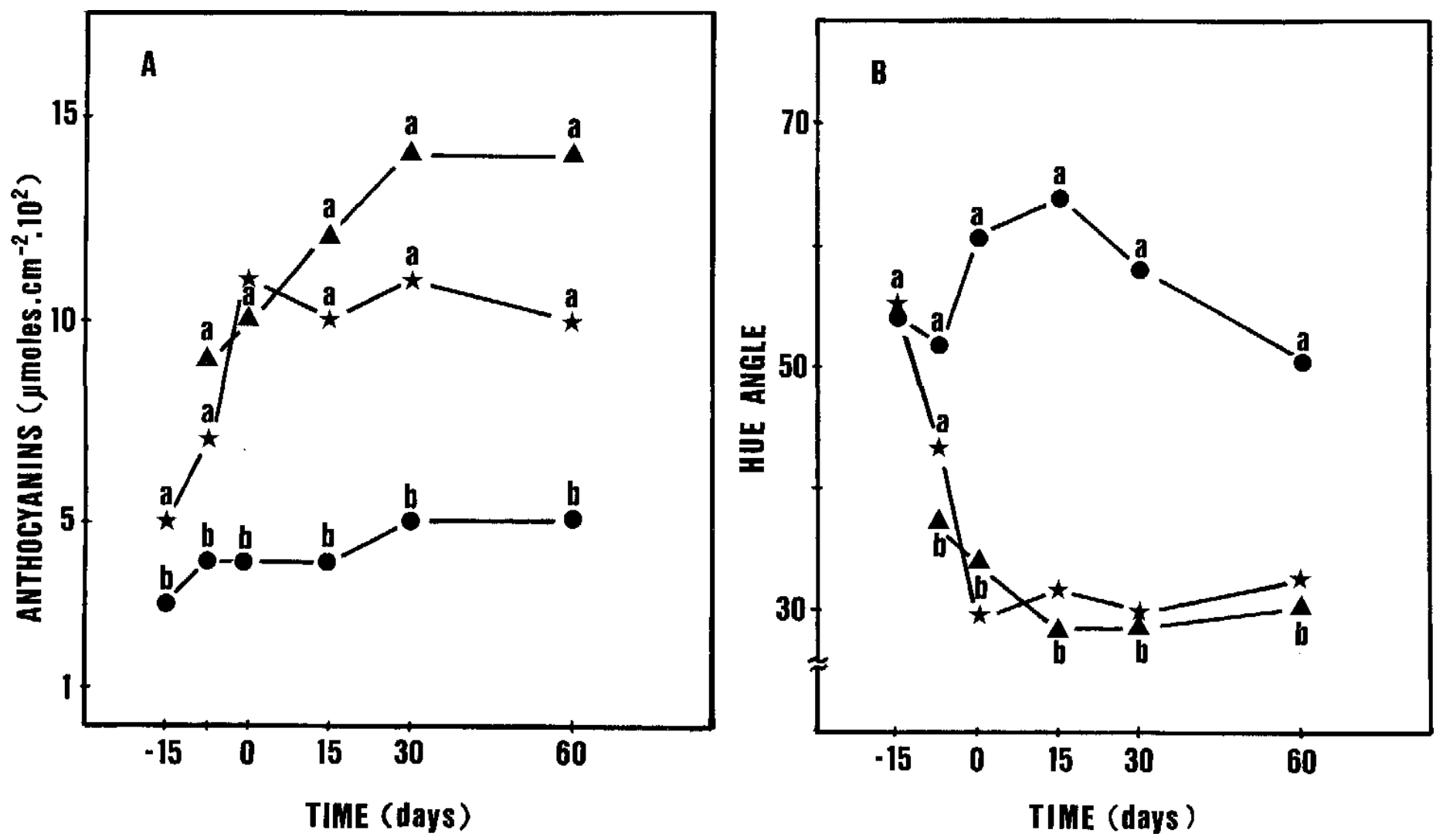

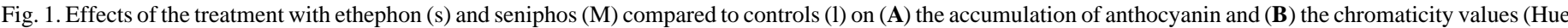

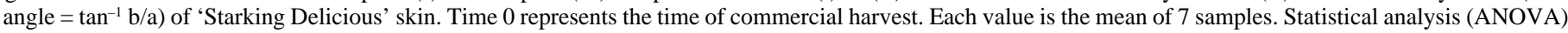

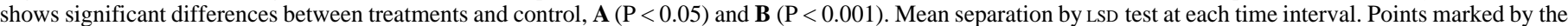
same letter are not significantly different (LSD < 0.05$)$. 


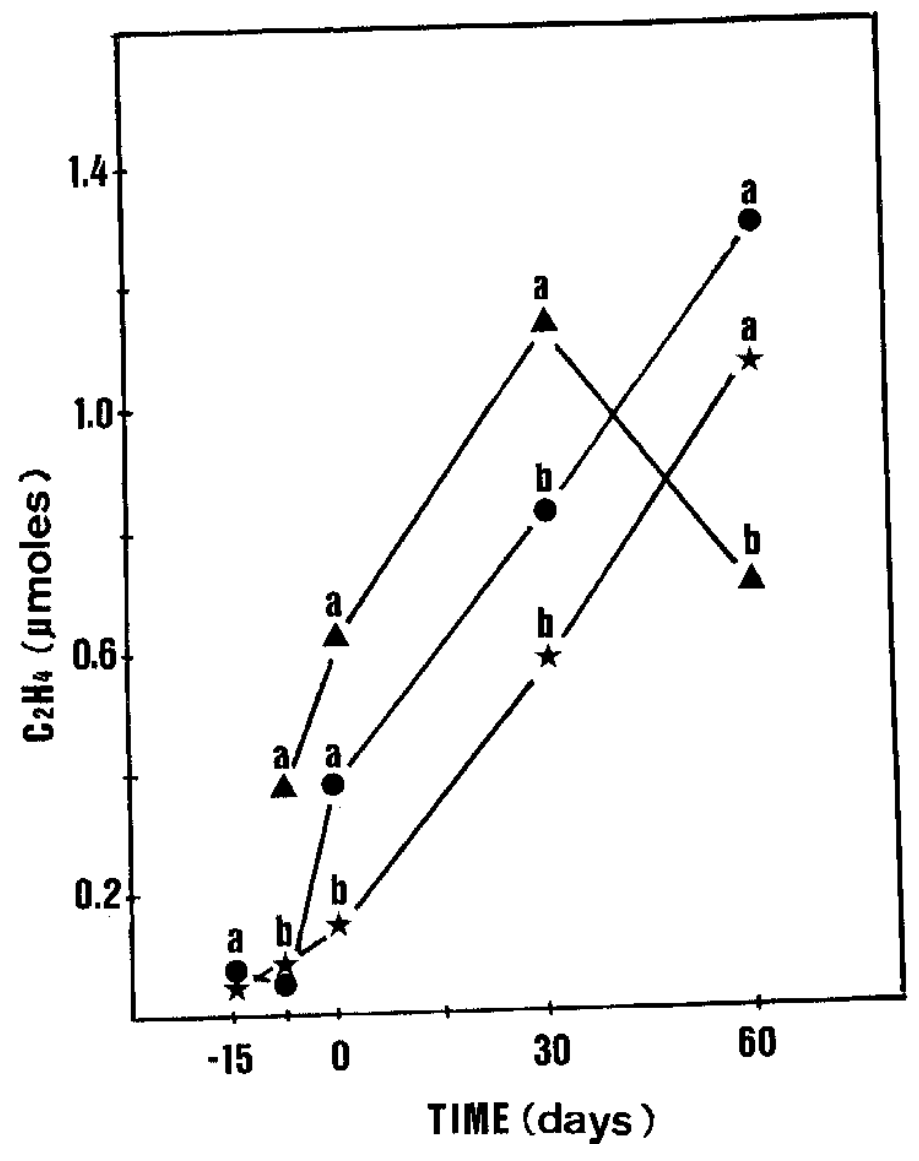

Fig. 2. Effects of the treatment with ethephon (s) and seniphos (M) compared to controls (1) on the internal ethylene concentration of 'Starking Delicious' apples. Time 0 represents the time of commercial harvest. Each value is the mean of 7 samples. Statistical analysis (ANOVA) shows significant differences between treatments $(P<0.001)$. Mean separation by LSD test at each time interval. Points marked by the same letter are not significantly different (LSD < 0.05 ).

until harvest (day 0 of the figure) but ceased when apples were placed in cold storage. Ethephon-treated apples showed an increase in color during cold storage for about $30 \mathrm{~d}$ for anthocyain content and $15 \mathrm{~d}$ for the hue angle value.

Ethylene biosynthesis. At harvest the seniphos-treated apples showed lower internal ethylene concentrations than control fruit (Fig. 2). Ethylene concentration in the ethephon-treated fruit was significantly higher than in seniphos-treated fruit until day 30 but declined thereafter.

Ethephon treatment greatly increased the ACC oxidase activity in the skin during the preharvest period (Fig. 3), but a sharp fall in activity was observed from day -8 to day +30 . Seniphos-treated apples did not show this high increase in activity during the preharvest period. ACC oxidase activity in these fruit peaked at the same time as control fruit but at a value twice that of untreated fruit. The activity rose again to values similar to ethephon-treated fruit.

Differences in ACC levels between treatments were not significant except between treated and non treated fruit at day 60 (Fig. 4). They were constant and very low before harvest and increased steadily during cold storage. MACC levels were significantly higher in ethephon-treated apples than in seniphos-treated fruit (Fig. 5) that showed low levels until day 30.

PAL activity. Before treatment, PAL activity in the skin was low (Fig. 6). All treatments sharply increased in activity up to 1.5, 2.3, and $2.8 \mathrm{nkat} \cdot \mathrm{kg}^{-1}$ for the control, ethephon and seniphos-treated fruit, respectively. The activity then decreased until day 7 and

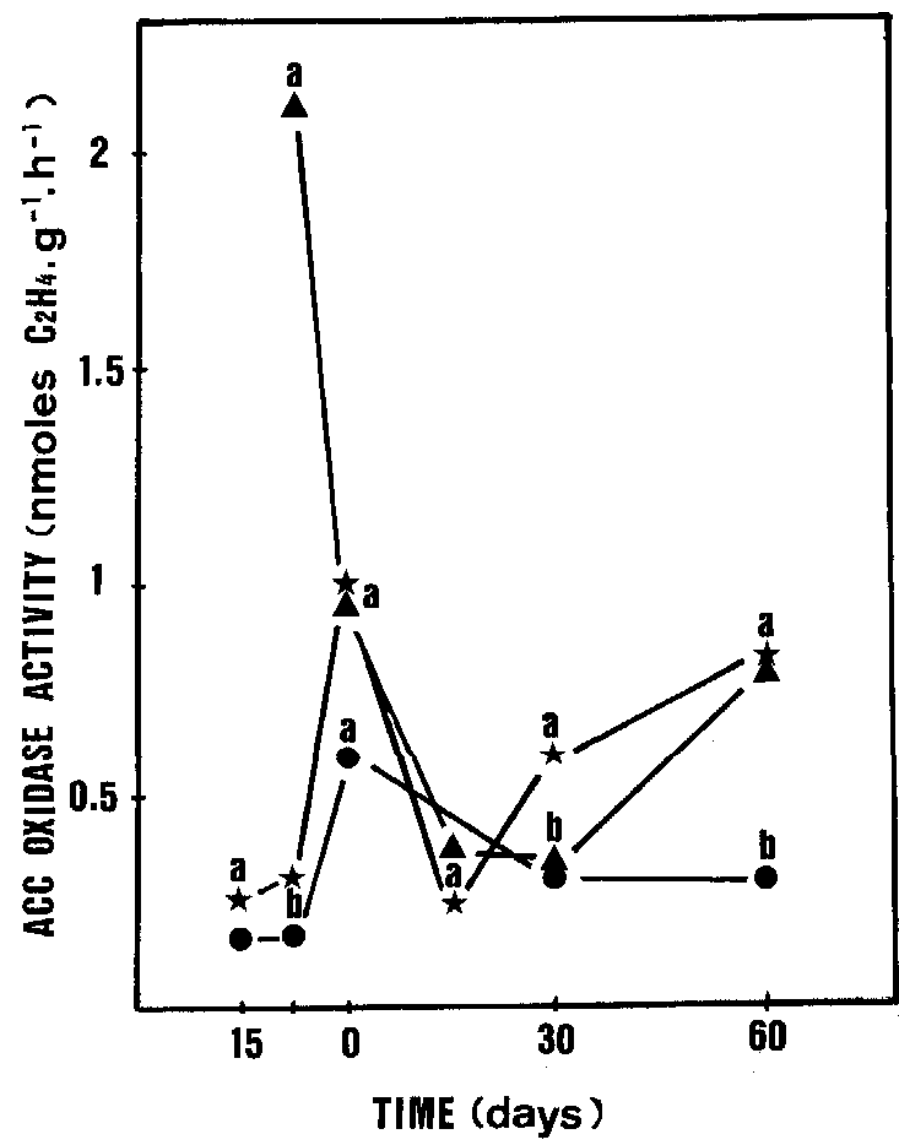

Fig. 3. Effects of the treatment with ethephon (s) and seniphos (M) compared to controls (1) on ACC oxidase activity in peel of 'Starking Delicious' apples. Time 0 indicate the time of commercial harvest. Each value is the mean of 3 samples. Statistical analysis (ANOVA) shows significant differences between treatments $(P<0.05)$. Mean separation by LSD test at each time interval. Points marked by the same letter are not significantly different $($ LSD $<0.05)$.

stabilized. The ethephon and seniphos-treated fruit remaining at a higher value than control fruit until day 20.

Effects on quality. The seniphos-treated fruit showed higher fruit firmness after harvest and during cold storage than the ethephon-treated apples (Table 1). In 1992, SSC content was

Table 1. Effects of the ethephon and seniphos treatment on fruit firmness and soluble solids concentration (SSC) of 'Starking Delicious' apples in 1992. Samples were analyzed at harvest and after $60 \mathrm{~d}$ in $1^{\circ} \mathrm{C}$ storage. ${ }^{\mathrm{z}}$

\begin{tabular}{lcc}
\hline \hline & $\begin{array}{c}\text { Firmness }^{\mathrm{y}} \\
(\mathrm{N})\end{array}$ & $\begin{array}{r}\text { Soluble solids } \\
\operatorname{concn}^{\mathrm{y}}(\%)\end{array}$ \\
\hline Control & $\begin{array}{c}\text { Harvest } \\
\text { Ethephon }\end{array}$ & $13.8 \mathrm{ab}$ \\
Seniphos & $64.3 \mathrm{a}$ & $14.5 \mathrm{a}$ \\
& $77.5 \mathrm{a}$ & $13.2 \mathrm{~b}$ \\
Control & 60 d after harvest & $14.9 \mathrm{a}$ \\
Ethephon & $61.5 \mathrm{a}$ & $14.4 \mathrm{a}$ \\
Seniphos & $55.7 \mathrm{~b}$ & $13.5 \mathrm{~b}$
\end{tabular}

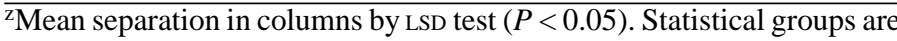
designated with letters within the body of the table.

${ }^{y}$ Means of seven replicates. 
Table 2. Differences between years in firmness $(\mathrm{N})$ and soluble solids concentration (SSC in \%) at harvest in 'Starking Delicious' apples treated with ethephon and seniphos. ${ }^{\mathrm{z}}$

\begin{tabular}{lcc}
\hline & Firmness $^{\mathrm{y}}$ & SSC $^{\mathrm{y}}$ \\
\hline & 1992 & \\
Controls & $75.3 \mathrm{a}$ & $13.8 \mathrm{ab}$ \\
Ethephon & $64.6 \mathrm{~b}$ & $14.5 \mathrm{a}$ \\
Seniphos & $77.5 \mathrm{a}$ & $13.2 \mathrm{~b}$ \\
& 1993 & \\
Controls & $73.0 \mathrm{a}$ & $10.8 \mathrm{a}$ \\
Ethephon & $66.4 \mathrm{~b}$ & $12.9 \mathrm{~b}$ \\
Seniphos & $71.7 \mathrm{a}$ & $11.2 \mathrm{a}$ \\
& 1994 & \\
Controls & $79.1 \mathrm{a}$ & $15.0 \mathrm{a}$ \\
Ethephon & $71.8 \mathrm{a}$ & $15.6 \mathrm{a}$ \\
Seniphos & $76.0 \mathrm{a}$ & $13.7 \mathrm{~b}$ \\
\hline
\end{tabular}

${ }^{\mathrm{z}}$ Mean separation in columns by LSD test $(P<0.05)$. Statistical groups are designated with letters within the body of the table.

${ }^{y}$ Means of seven replicates.

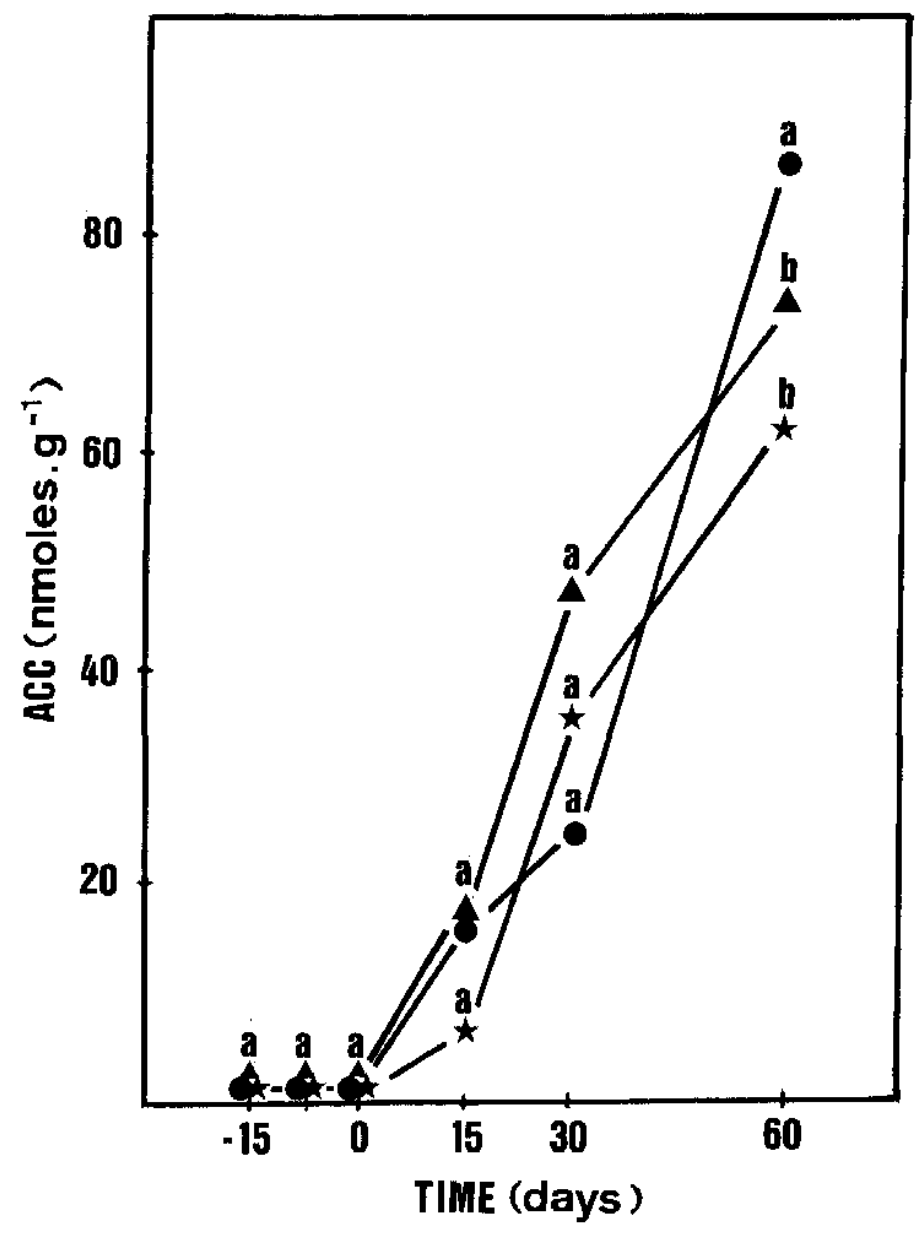

Fig. 4. Changes in the levels of ACC in 'Starking Delicious' skin after different treatments: control (1), fruit treated with ethephon (s), fruit treated with seniphos (M). Time 0 indicate the time of commercial harvest. Each value is the mean of three samples. Statistical analysis (ANOVA) shows no significant differences between treatments. Mean separation by LSD test at each time interval. Points marked by the same letter are not significantly different (LSD < 0.05$)$. slightly higher at harvest in the ethephon-treated apples compared to controls, and were lower in the seniphos-treated fruit at harvest and after storage.

Although there are differences between years, seniphos treatment led to lower SSC content and higher firmness than ethephon (Table 2 ). Seniphos-treated fruit were similar to controls.

\section{Discussion}

Color improvement was observed by the reflectometric analysis (Fig. 1B) and by an increase in anthocyanin content (Fig. 1A). Establishment of a direct relationship between these two analytical procedures is difficult. The reflectometric method is a physical method representative of the visual appearance but the anthocyanin determination only estimates the content of one type of pigment, the cyanidin-3-galactoside (Recasens et al., 1982). As a consequence, the increase in anthocyanin content observed in the treated apples during storage (Fig. 1A) was not correlated with an increase of the Hue angle (Fig. 1B) or with the visual perception of color.

Although the seniphos and ethephon significantly improved the peel color of the fruit, there was a differential effect, particularly during cold storage. Ethephon has a relatively high energy of

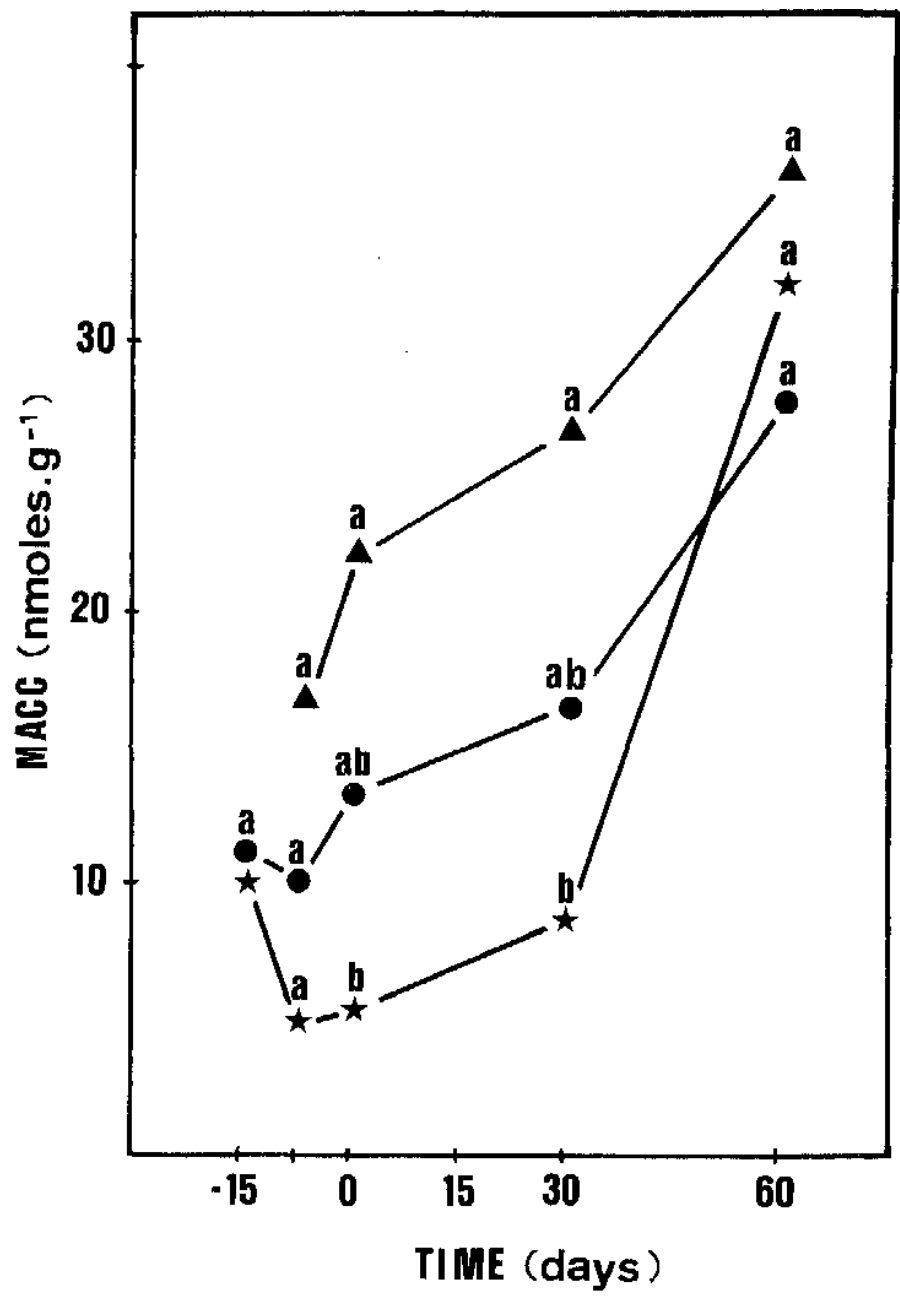

Fig. 5. Changes in the levels of MACC in 'Starking Delicious' skin after different treatments: control (1), fruit treated with ethephon (s), fruit treated with seniphos (M ). Time 0 indicate the time of commercial harvest. Each value is the mean of three samples. Statistical analysis (ANOVA) shows significant differences between treatments $(P<0.05)$. Mean separation by LSD test at each time interval. Points marked by the same letter are not significantly different (LSD < 0.05$)$. 


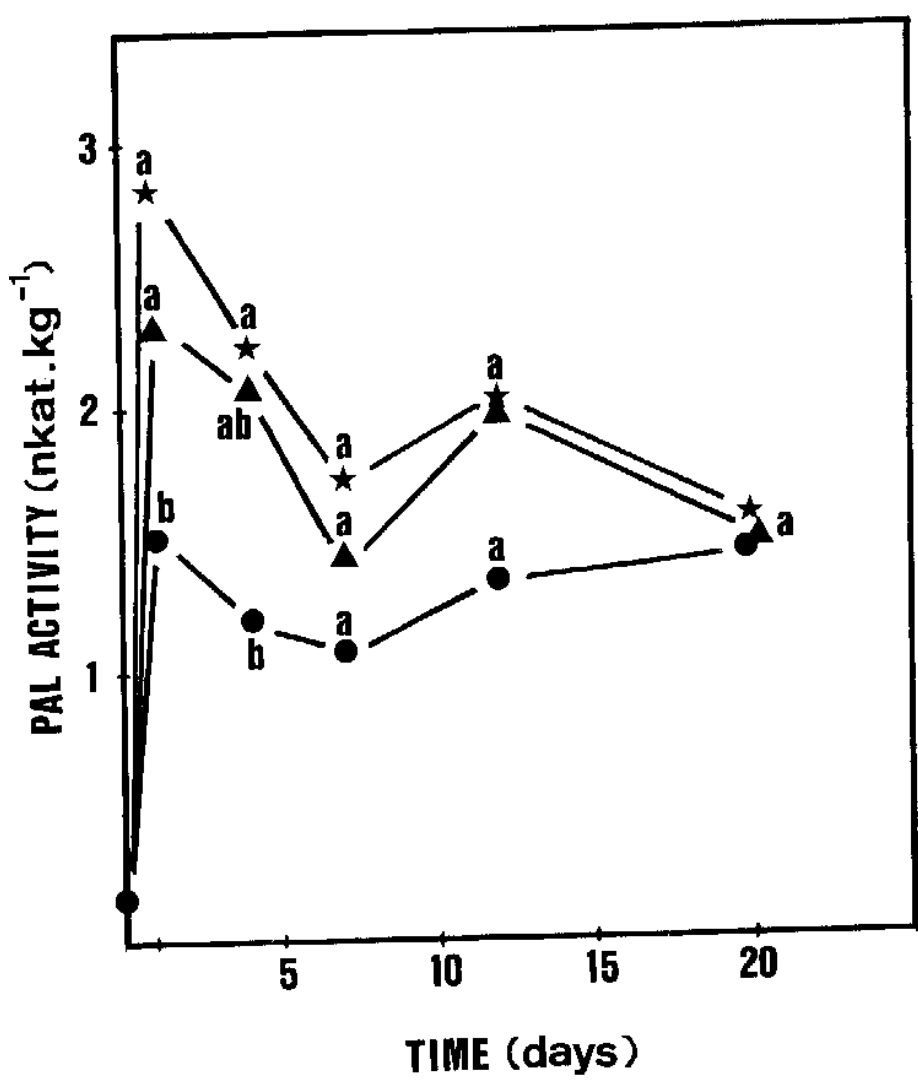

Fig. 6. Effects of the treatment with ethephon (s) and seniphos (M) compared to controls (1) on PAL activity in peel of 'Starking Delicious' apples. Each value is the mean of three samples. Statistical analysis (ANOVA) shows significant differences between treatments $(P<0.001)$. Mea separation by LSD test at each time interval. Points marked by the same letter are not significantly different (LSD $<0.05)$.

activation and decomposes slowly (Murphey and Dilley, 1988) especially in cold conditions. In contrast, seniphos is not an ethylene-releasing compound. This differential sensitivity to cold probably reflects different chemical processes. Ethephon improves fruit color probably through ethylene action. Color improvement involves an activation of ACC oxidase (Fig. 3), which is rapid (maximal during the preharvest period) and associated with a slight increase in internal ethylene concentration. Concomitantly ethephon also increases ACC metabolism, particularly through an enhancement of MACC levels, which are probably ethylene promoted (Liu et al., 1985b). Ethephon treatment also promoted PAL activity (Fig. 6). The increase is rapid and directly related to the increase of anthocyanin biosynthesis (Blankenship and Unrath, 1988, Farragher and Chalmers, 1977; Farragher and Brohier, 1984). A lower but significant increase in PAL activity was also noted in control fruit. This increase was probably related to the cooling effect of water treatment.

The mode of action of seniphos remains unclear. As shown in Fig. 2, the color improvement was not ethylene related but involved an activation of PAL enzyme. Reports that $\mathrm{Ca}\left(\mathrm{H}_{2} \mathrm{PO}_{4}\right)$ sprays can increase apple fruit $\mathrm{P}$ and Ca concentrations (Johnson and Yogaratnam, 1978; Yogaratnam and Sharples, 1982), suggest that the seniphos treatment increases mineral uptake by apples. Improvements of color and quality may have been merely a consequence of a change in the mineral composition of the fruit. Physiological processes associated with this mineral change might include a modification of the enzyme phosphorylation status and/ or in the action of the $\mathrm{Ca}$ as a second messenger.

In 1992 and 1993 (Table 2), the ethephon treatment clearly advanced ripening in 'Starking Delicious' apples. In contrast, the seniphos-treated apples compared to controls remained unchanged and showed similar firmness values and sometimes less SSC. After cold storage (Table 1), these differences in quality were maintained for both treatments. Color improvement was different between years (result not shown). This difference was probably the reflection of various climatic conditions. The higher the temperature, the lower the color improvement. However, seniphos improved color without advancing ripening in all years.

The color improvement by ethephon is accompanied by other less desirable effects such as stimulation of ripening. The use of seniphos seems to be promising, since it stimulates anthocyanin accumulation without activation of ethylene production and subsequent ripening.

\section{Literature Cited}

Blankenship, S.M. and C.R. Unrath. 1988. PAL and ethylene content during maturation of Red and Golden Delicious apples. Phytochemistry 27:1001-1003.

Chalmers, D.J., J.D. Faragher, and J.W. Raff. 1973. Changes in anthocyanin synthesis as an index of maturity in red apple varieties. J. Hort. Sci. 48:387-392.

Cheng, G.W. and P.J. Breen. 1991. Activity of phenylalanine-ammonialyase (PAL) and concentrations of anthocyanins and phenolics in developing strawberry fruit. J. Amer. Soc. Hort. Sci. 116:865-869.

Faragher, J.D. and D.J. Chalmers. 1977. Regulation of anthocyanin synthesis in apple skin. III: Involvement of phenylalanine ammonialyase. Austral. J. Plant Physiol. 4:133-141.

Faragher, J.D. and R.L. Brohier. 1984. Anthocyanin accumulation in apple skin during ripening: Regulation by ethylene and phenylalanine ammonia-lyase. Scientia Hort. 22:89-96.

Hoffman, N.E., S.F. Yang, and T. McKeon. 1982. Identification of 1(malonylamino) cyclopropane-1-carboxylic acid as a major conjugate of 1-aminocyclopropane-1-carboxylic acid, an ethylene precursor. Biochem. Biophys. Res. Commun. 104:765-770.

Johnson, D.S. and N. Yogaratnam. 1978. The effects of phosphorus sprays on the mineral composition and storage quality of Cox's Orange Pipin apples. J. Hort. Sci. 53:171-178.

Liu, Y., N.E. Hoffman, and S.F. Yang. 1985a. Promotion by ethylene of the capability to convert 1-aminocyclopropane-1-carboxylic acid to ethylene in preclimacteric tomato and cantaloupe fruits. Plant Physiol. 77:407-411.

Liu, Y., L.Y. Su, and S.F. Yang. 1985b. Ethylene promotes the capability to malonylate $\mathrm{ACC}$ and $\mathrm{D}$-amino acids in preclimacteric tomato fruits. Plant Physiol. 77:891-895.

Lizada, M.C.C. and S.F. Yang . 1979. A simple and sensitive assay for 1aminocyclopropane-1-carboxylic acid. Anal. Biochem. 100:140-145.

Maynard, J.A. and J.M Swan. 1963. Organophosphous compounds. I: 2chloroalkylphosphonic acid as phosphorylating agents. Austral. J. Chem. 16:596-612.

McGuire, R.G. 1992. Reporting of objective color measurements. HortScience. 27:1254-1255.

Murphey, A.S. and D. Dilley. 1988. Anthocyanin biosynthesis and maturity of McIntosh apples as influenced by ethylene-releasing compounds. J. Amer. Soc. Hort. Sci. 113:718-723.

Recasens, I. 1982. Estudio de diversos parametros fisiologicos durante el crecimiento del fruto. Aplicación a la manzana 'Starking Delicious'. PhD diss., Barcelone Univ., Bellaterra. (Abstr.)

Salunkhe D.K., H.R. Bolin, and N.R. Reddy. 1991. Storage processing and nutritional quality of fruit and vegetable. vol. I: Fresh fruit and vegetables. 2nd ed. CRC Press.

Tan, S.C. 1979. Relationships and interactions between phenylalanine ammonia-lyase, phenylalanine ammonia-lyase inactivating system, and anthocyanin in apples. J. Amer. Soc. Hort. Sci. 104:581-586.

Yogaratnam, N. and R.O. Sharples. 1982. Supplementing the nutrition of Bramley's Seedling apples with phosphorus sprays. II: Effects on fruit composition and storage quality. J. Hort. Sci. 57:53-59. 